Background: Although the levels of immunoglobulin $E$ (IgE) in the circulating blood are often elevated in patients with allergic diseases, such levels cannot always be considered as pathognomonic signs of allergy. The induction of allergic reactions in the tissue was inferred to be related to the amount of IgE passing through the vascular wall.

Aims: We attempted to clarify which compartment, the intravascular or extravascular, plays an important role in the regulation of the turnover of rat IgE. Methods: The level of DNP-specific rat IgE in the serum was estimated by IgE-capture enzyme-linked immunosorbent assay, and the turnover of IgE was analyzed from its pharmacokinetic parameters.

Results: The transfer rate constants from the central to tissue compartment $\left(K_{\mathrm{ct}}\right)$ were larger than those from the tissue to central compartment $\left(K_{\text {tc }}\right)$ irrespective of the sensitized state. The value of the distribution volume of the tissue compartment $\left(V_{t}\right)$ was larger than that of the distribution volume of the central compartment $\left(V_{c}\right)$ irrespective of the sensitized state.

Conclusions: These findings suggest that the short half-life of rat IgE in the circulation could be attributable to the distribution of IgE from the intravascular to the extravascular compartment.

Key words: Rodent, Allergy, Antibodies, IgE turnover, In vivo animal models

\section{Analysis of $\lg E$ turnover in non-sensitized and sensitized rats}

\author{
Kazuhiko Hanashiro ${ }^{1, C A}$, Yoshihiro Tokeshi ${ }^{1}$, \\ Toshiyuki Nakasone ${ }^{1,2}$, Masanori Sunagawa ${ }^{1}$, \\ Mariko Nakamura ${ }^{1}$ and Tadayoshi Kosugi ${ }^{1}$
}

${ }^{1} 1$ st Department of Physiology and ${ }^{2}$ Department of Oral and Maxillofacial Surgery, School of Medicine, University of the Ryukyus, 207 Uehara, Nishihara, Okinawa 903-0215, Japan

\author{
${ }^{\mathrm{CA}}$ Corresponding Author \\ Tel: +8198 8951108 \\ Fax: +81988951402 \\ E-mail: tkosugi@med.u-ryukyu.ac.jp
}

\section{Introduction}

The levels of immunoglobulin E (IgE) in the circulating blood are often elevated in patients with allergic diseases. However, such levels cannot be considered as pathognomonic signs of allergy. Our previous data have suggested that airway responses in Wistar rats appeared more easily when the IgE levels decreased than when they increased. ${ }^{1}$ The induction of allergic reactions in the tissue was inferred therefore to be related to the amount of IgE, which passes through the vascular wall, the catabolism of IgE in the extravascular compartment and/or cellular conditions, i.e. the number, heterogeneity and development of mast cells. It is thus important to investigate the turnover of IgE in the circulating blood when attempting to clarify the mechanisms of allergic reactions occurring in the tissue. On the contrary, IgE is known to exhibit the highest fractional catabolic rate, and a half-life of $24-48 \mathrm{~h}$ in humans as compared with 10-14 days for IgG. ${ }^{2-4}$ The hypothesis has been put forward that an increased catabolic rate of IgE is dependent on the existence of intravascular and/or extravascular compartments capable of specifically clearing the IgE. ${ }^{4}$ Human $\operatorname{IgE}$ is reported to be metabolized mainly in the extravascular compartment and the catabolism of IgE is related to the interaction of IgE with Fc $\varepsilon$ receptor-bearing cells. ${ }^{2-4}$ In contrast, it has also been speculated that the vascular endothelium represents a site of catabolism of IgE based on experiments that indicated catabolism is a diffuse process not dependent on any one organ. ${ }^{4}$ Rat IgE has been reported by Tada $e t a l^{5}$ to have an extremely short half-life (approximately $12 \mathrm{~h}$ ) in the circulation. However, the turnover of IgE in the circulating blood and patterns of distribution of IgE in the rat have not been investigated by analyzing the metabolic parameters of IgE. In the present study, we examined which compartment, the intravascular or extravascular, plays an important role in the regulation of the turnover of $\operatorname{IgE}$ in rats.

\section{Materials and methods}

\section{Animals}

Wistar strain male rats weighing 250-300g (Kyudo Co., Ltd., Kumamoto, Japan) were employed in the experiments. Ten Wistar rats were divided into two groups, each consisting of five rats. Group A was untreated, and group B was sensitized with ovalbumin (OVA). One milligram of OVA suspended in $0.5 \mathrm{ml}$ of 
saline was mixed with killed Bordetella pertussis $\left(10^{10}\right.$ cells) according to the method of Tada and Okumura. ${ }^{6}$ This mixture was divided into aliquots (four solutions) and injected subcutaneously into the footpads of the rats to be sensitized. At 5 days after the first sensitization, the rats were boosted with $0.5 \mathrm{mg}$ of OVA suspended in $0.25 \mathrm{ml}$ of physiological saline. Cannulation of the jugular vein was performed according to the method of Nakasone $e t a .^{7}$ The cannulation of the animals for the administration of IgE and blood sampling was carried out at day 6 after the first sensitization. Estimations of the passive cutaneous anaphylaxis (PCA) titers in the serum of rats sensitized with OVA were carried out according to the method of Tada and Okumura. ${ }^{6}$

We followed the Standards Relating to the Care and Management of Experimental Animals (Notification No. 6, 27 March 1980, Prime Minister's Office, Tokyo, Japan) for the care and use of the animals, together with the guide for animal experiments issued by the University of the Ryukyus. All animal studies were reviewed and approved by the Animal Care Committee at the University of the Ryukyus.

\section{Reagents}

2,4-Dinitrobenzene sulfonic acid sodium salt was purchased from Tokyo Kasei Inc., Ltd. (Tokyo, Japan), and killed B. pertussis from Kaken Chemical Ltd. (Osaka, Japan). Chicken egg albumin (OVA) and 2,2'-azino-di-[3-ethyl-benzthiazoline-6-sulfonic acid] were purchased from Sigma Chemical Co. (St. Louis, MO, USA). Tween 20 and gelatin fine powder were obtained from Nacalai Tesque (Kyoto, Japan), and hydrogen peroxide from Santoku Chemical Ind. (Miyagi, Japan). Aminohexanoyl-biotin- $\mathrm{N}$-hydroxysuccinimide, peroxidase-conjugated streptavidin and mouse anti-rat myeloma IgE (MARE-1) were obtained from Zymed Laboratories (San Francisco, CA, USA). Intramedic polyethylene tubing (inner diameter, $0.28 \mathrm{~mm}$; outer diameter, $0.61 \mathrm{~mm}$ ) was purchased from Becton Dickinson and Company (Franklin Lakes, $\mathrm{NJ}$, USA). Unless otherwise stated, all other chemicals were of reagent grade.

\section{Preparation of monoclonal dinitrophenyl-specific rat lgE}

The procedure employed for the preparation of monoclonal dinitrophenyl (DNP)-specific rat IgE was a modification of that described previously. ${ }^{8}$ Cultured medium from rat IgE-secreting hybridoma (FE-3) was applied to a column of DNP-BSA-Sepharose $4 \mathrm{~B}$. The adsorbed protein was eluted with $90 \mathrm{mM}$ DNP-glycine (pH 8.2). Free DNP-glycine was removed by dialysis against several changes of Dulbecco's phosphatebuffered saline. This procedure was repeated twice at $4^{\circ} \mathrm{C}$, and a single band was observed at $200 \mathrm{kDa}$ on sodium dodecyl sulfate-polyacrylamide gel electrophoresis and Western blot analysis utilizing mouse anti-rat myeloma IgE for the protein obtained.

\section{Administration of monoclonal DNP-specific rat IgE and blood sampling}

Two milligrams of monoclonal DNP-specific rat IgE was given intravenously to the rats sensitized with OVA at day 8 after the first sensitization and to the normal rats via the jugular vein cannula. Blood samples of $0.5 \mathrm{ml}$ were taken from the jugular vein cannula and an identical volume of physiological saline was subsequently injected at $15 \mathrm{~min}$, and 1,3 , 6,12 and $24 \mathrm{~h}$ after the administration of IgE. The serum was kept at $-20^{\circ} \mathrm{C}$ until determination of its IgE levels.

\section{IgE-capture enzyme-linked immunosorbent assay for estimation of monoclonal DNP-specific rat IgE}

The IgE-capture enzyme-linked immunosorbent assay (ELISA) for estimating rat IgE antibodies to DNP-As was performed as described previously. ${ }^{8}$

\section{Calculation of pharmacokinetic parameters}

Best-fit curves for the concentration of monoclonal DNP-specific rat IgE versus time were plotted by leastsquares linear regression analysis. The resultant curves exhibited the biexponential pattern characteristics of a two-compartment model. Semi-logarithmic plots of the concentration of IgE were of the form $C c=A e^{-\alpha_{t}}$ $+B e^{-\beta_{t}}$, where $C c$ represents the concentration of monoclonal DNP-specific rat IgE in the serum at a given time $(t), A$ and $B$ denote the respective intercepts of the initial and terminal phases, and the coefficients $\alpha$ and $\beta$ were derived graphically from the slopes of the biphasic curves. Compartment models were fitted for serum concentration against time course of IgE, and the pharmacokinetic parameters were then calculated from the values obtained, as hybrid parameters (involving $A, B, \alpha$ and $\beta)$. The apparent first-order intercompartmental rate constants $\left(K_{\mathrm{ct}}\right.$ and $\left.K_{\mathrm{tc}}\right)$, the tissue concentration of IgE, the distribution volume of the central compartment $\left(V_{\mathrm{c}}\right)$ and tissue compartment $\left(V_{\mathrm{t}}\right)$, and other pharmacokinetic parameters were derived from the equations described by Rowland and Tozer. ${ }^{9}$

\section{Statistical analysis}

Statistical analysis was performed by the unpaired Student's $t$-test for between-group comparisons. Data are expressed as the means \pm standard deviation (SD). When a $p$ value less than 0.05 was obtained, the means were considered to be significantly different. 


\section{Results}

Changes of PCA titer following sensitization with OVA

The PCA titer in the serum of the rats sensitized with OVA increased to its highest value between day 8 and day 10 (Fig. 1A). Monoclonal DNP-specific rat IgE was therefore administered to the rats at day 8 after the first sensitization with OVA in subsequent experiments.

\section{Dose-response curve in IgE-capture ELISA for} monoclonal DNP-specific rat IgE

The absorbance level in the serum of OVA-sensitized rats with IgE administration was correlated with the dilution of the serum. However, the absorbance level in the serum of OVA-sensitized rats without IgE administration was not correlated with the dilution of the serum (Fig. 1B). It was evident, therefore, that DNP-specific IgE administered to rats could be determined by the procedure of IgE-capture ELISA employed.

\section{Serum concentration-time curves for monoclonal DNP-specific rat IgE in rats following intravenous (i.v.) administration}

The level of monoclonal DNP-specific rat IgE in the serum underwent a rapid decrease between $15 \mathrm{~min}$ and $3 \mathrm{~h}$, and then declined slowly between 6 and $24 \mathrm{~h}$ following i.v. administration irrespective of the sensitized state. The IgE levels at $15 \mathrm{~min}-3 \mathrm{~h}$ and at 6-24 h, respectively, displayed broadly linear decreases on semi-logarithmic graphs (Fig. 1C). The turnover of monoclonal DNP-specific rat IgE administered to the rats was therefore analyzed using a two-compartment model for the pharmacokinetics.

FIG. 1. (A) Changes in PCA titer following sensitization with OVA. Three Wistar rats were employed as recipients. Data are expressed as means $\pm \mathrm{SD}(n=3)$. (B) Dose-response curve in IgE-capture ELISA for monoclonal DNP-specific rat IgE. Open circles, Serum of Wistar rats sensitized with OVA at day 8; closed circles, serum of Wistar rats sensitized with OVA and administered with monoclonal DNP-specific rat $\mathrm{lgE}$ at day 8 . The serum was diluted with $2 \%$ gelatin-PBST (Dulbecco's phosphate-buffered saline containing $0.05 \%$ Tween 20 ). Data are expressed as means $\pm \operatorname{SD}(n=5)$. (C) Serum concentrationtime curves for monoclonal DNP-specific rat IgE in rats following i.v. administration. Two milligrams of monoclonal DNPspecific rat IgE was administered to rats via the jugular vein. Open circles, Non-sensitized rats (group A); closed circles, OVAsensitized rats (group B). Data are expressed as means \pm SD $(n=5)$. (D) Tissue concentration-time curves for monoclonal DNP-specific rat IgE in rats following i.v. administration. Two milligrams of monoclonal DNP-specific rat IgE was administered to rats via the jugular vein. Open circles, Non-sensitized rats (group A); closed circles, OVA-sensitized rats (group B). Data are expressed as means $\pm \mathrm{SD}(n=5)$. 
Tissue concentration-time curves for monoclonal DNP-specific rat IgE in rats following i.v. administration

The tissue concentration of monoclonal DNP-specific rat IgE was calculated, and found to increase to its highest value at between 1 and $3 \mathrm{~h}$ following i.v. administration to the rats irrespective of the sensitized state (Fig. 1D).

\section{Pharmacokinetic parameters}

No significant differences in distribution half-life $\left(t_{1 / 2} \alpha\right)$ were observed between the non-sensitized and OVAsensitized rats. The elimination half-life $\left(t_{1 / 2} \beta\right)$ of monoclonal DNP-specific rat IgE was about $12 \mathrm{~h}$ following i.v. administration to the rats irrespective of the sensitized state. The transfer rate constants from the central to tissue compartment $\left(K_{\mathrm{ct}}\right)$ were larger than those from the tissue to central compartment $\left(K_{\mathrm{tc}}\right)$ irrespective of the sensitized state $(\phi<0.05)$. The value of the distribution volume of the tissue compartment $\left(V_{\mathrm{t}}\right)$ was larger than that of the distribution volume of the central compartment $\left(V_{\mathrm{c}}\right)$ irrespective of the sensitized state (group A, $p<0.05$; group $\mathrm{B}, p<0.01$ ). No significant difference was observed in the other pharmacokinetic parameters, including the elimination rate constant $\left(K_{\mathrm{el}}\right)$, the area under the serum concentration-time curve (AUC) and the total body clearance $\left(\mathrm{CL}_{\text {total }}\right)$, in the present study (Table 1$)$.

\section{Discussion}

The half-life of rat IgE in the circulating blood has been reported by Tada $e t a l .^{5}$ to be about $12 \mathrm{~h}$. In

Table 1. Pharmacokinetic parameters for monoclonal DNPspecific rat IgE administered to non-sensitized and OVAsensitized rats

\begin{tabular}{lcc}
\hline Parameter & $\begin{array}{c}\text { Group A } \\
\text { (non-sensitized) }\end{array}$ & $\begin{array}{c}\text { Group B } \\
\text { (OVA-sensitized) }\end{array}$ \\
\hline$A(\mu \mathrm{g} / \mathrm{ml})$ & $15.36 \pm 7.71$ & $16.42 \pm 13.47$ \\
$B(\mu \mathrm{g} / \mathrm{ml})$ & $1.67 \pm 0.97$ & $1.30 \pm 0.39$ \\
$\alpha(/ \mathrm{h})$ & $2.12 \pm 0.85$ & $1.78 \pm 0.26$ \\
$\beta(/ \mathrm{h})$ & $0.076 \pm 0.053$ & $0.063 \pm 0.020$ \\
$K_{\mathrm{el}}(/ \mathrm{h})$ & $0.49 \pm 0.22$ & $0.52 \pm 0.28$ \\
$K_{\mathrm{tc}}(/ \mathrm{h})$ & $0.27 \pm 0.05$ & $0.26 \pm 0.14$ \\
$K_{\mathrm{ct}}(/ \mathrm{h})$ & $1.45 \pm 0.85^{*}$ & $1.63 \pm 0.82^{*}$ \\
$V_{\mathrm{c}}(/ \mathrm{kg})$ & $0.57 \pm 0.29$ & $0.75 \pm 0.69$ \\
$V_{\mathrm{t}}(/ \mathrm{kg})$ & $3.47 \pm 2.75^{* *}$ & $3.38 \pm 0.90^{* * *}$ \\
$t_{1 / 2 \alpha}(\mathrm{h})$ & $0.35 \pm 0.12$ & $0.40 \pm 0.06$ \\
$t_{1 / 2 \beta}(\mathrm{h})$ & $13.06 \pm 5.66$ & $12.00 \pm 3.90$ \\
$\mathrm{CL}$ & $247.64 \pm 100.76$ & $264.65 \pm 138.23$ \\
$\mathrm{AUC}(\mathrm{ml} / \mathrm{h} / \mathrm{hl})$ & $31.48 \pm 15.38$ & $31.43 \pm 15.47$ \\
\end{tabular}

Two milligrams of monoclonal DNP-specific rat IgE was administered to rats via the jugular vein. Data are expressed as means $\pm \operatorname{SD}(n=5)$. AUC, Area under the serum concentration-time curve; $\mathrm{CL}_{\text {total }}$, total body clearance. ${ }^{*} p<0.05, K_{\mathrm{ct}}$ versus $K_{\mathrm{tc}}$ in each group; ${ }^{*} p<0.05$, *** $p<0.01, V_{\mathrm{t}}$ versus $V_{\mathrm{c}}$ in each group. the present study, the elimination half-life $\left(t_{1 / 2} \beta\right)$ of monoclonal DNP-specific rat IgE was found to be about $12 \mathrm{~h}$ following i.v. administration to rats irrespective of the sensitized state. These results are clearly consistent with each other. However, the aforementioned report ${ }^{5}$ did not describe the pattern of distribution and elimination of IgE in the rats, or the transfer rate of IgE between the circulation and tissue, since no investigations were made of the turnover of IgE through an analysis of the pharmacokinetic parameters. The results of the present study indicated that monoclonal DNP-specific rat IgE administered to rats was distributed to the extravascular compartment early in the experimental period irrespective of the sensitized state based on an analysis of the pharmacokinetic parameters, i.e. the intercompartmental rate constants $\left(K_{\mathrm{ct}}\right.$ and $\left.K_{\mathrm{tc}}\right)$ and distribution volumes $\left(V_{\mathrm{c}}\right.$ and $\left.V_{\mathrm{t}}\right)$. Although it remains to be clarified in which tissues the distribution of IgE was increased, the inference is that the short half-life of rat IgE could be attributable to the distribution of IgE from the intravascular to extravascular compartment. The mechanism of IgE catabolism in the intravascular and/or extravascular compartment remains unclear. The hypothesis has been put forward that an increased catabolic rate of IgE is dependent on the existence of intravascular and/or extravascular compartments capable of specifically clearing the $\operatorname{IgE}^{2-4}$ In addition, data have been reported that suggested there had been definite extravascular catabolism of IgE, whereas there had been no significant extravascular catabolism of the other three major immunoglobulin classes (IgG, IgA, and $\operatorname{IgM}){ }^{3}$ It was also proposed that such extravascular catabolism could be part of an unique catabolic mechanism specific for IgE that was related to unique interactions of IgE with basophils and mast cells. However, Isersky et al. ${ }^{10}$ found no evidence for cell-mediated IgE catabolism in their experiments employing basophilic leukemia cells. In addition, another report has indicated that the clearance of passively transferred IgE was not altered by mast cell deficiency in experiments on mast cell-deficient $\mathrm{W} / \mathrm{Wv}$ mice. ${ }^{11}$ On the contrary, receptor-mediated endocytosis of the IgE ligand has been shown to ensue after binding monomeric and DNP-BSA:IgE immune complexes, and the binding was inhibited by anti-CD23. ${ }^{12}$ It was suggested that normal Fc $\varepsilon$ RIIbearing mature $\mathrm{B}$ cells in the circulation and lymphoid tissues might function in the sequestration and catabolic turnover of IgE molecules through $\operatorname{IgE}$ or interleukin- 4 upregulated Fc $\varepsilon$ RII uptake. The present data and aforementioned reports could thus be interpreted to imply that the turnover of $\operatorname{IgE}$ is related mainly to the interaction of IgE with FceRIIbearing cells in the extravascular compartment.

Although studies on the relationship between the catabolic rate of IgE and IgE level in the circulation 
have been described by several investigators, their conclusions were manifold. The fractional catabolic rate in a patient with IgE myeloma was found to be decreased as compared with that in normal volunteers. ${ }^{4}$ It has been reported that the fractional catabolic rate for IgE was significantly less in atopic patients and in patients with hyperimmunoglobulin E-recurrent infection syndrome than in normal volunteers. $^{2}$ The data indicated that the fractional catabolic rate of IgE was inversely related to the serum IgE concentration. In the present study, monoclonal DNP-specific rat IgE was therefore administered to rats at day 8 when the OVA-specific IgE levels in the serum reached their highest values. However, no significant differences in kinetic parameters of IgE were noted between the non-sensitized and OVAsensitized rats. Similarly, Haba et al. ${ }^{13}$ demonstrated that the rates of clearance of inoculated IgE were approximately the same in mice bearing an IgEsecreting tumor and normal mice. In contrast, the IgE in trypanosome-infected cattle is known to have greatly increased catabolic rates as compared with that of normal uninfected cattle. ${ }^{14}$ Persistent high IgE levels are commonly observed for longer periods in patients with allergic diseases than in animal models. It is suggested therefore from our results and the aforementioned reports that the catabolic rate of IgE is dependent not only on the IgE level in the circulating blood, but also on differences in the development of $\mathrm{Fc} \varepsilon$ receptor-bearing cells, based on the duration of high IgE levels and the course, duration and/or pathway of sensitization with allergen.

\section{References}

1. Hanashiro K, Tamaki N, Koga T, Nakamura M, Kinjoh K, Kosugi T. Inhibitory effect of azelastine hydrochloride and suplatast tosilate on airway responses in sensitized rats following exposure to antigen. Int J Tissue React 1997; 19: 163-169.

2. Dreskin SC, Goldsmith PK, Strober W, Zech L, Gallin JI. Metabolism of immunoglobulin $\mathrm{E}$ in patients with markedly elevated serum immunoglobulin E levels. J Clin Invest 1987; 79: 1764-1772.

3. Iio A, Waldmann TA, Strober W. Metabolic study of human IgE: Evidence for an extravascular catabolic pathway. J Immunol 1978; 120: 1696-1701.

4. Waldmann TA, Iio A, Ogawa M, McIntyre OR, Strober W. The metabolism of IgE: studies in normal individuals and in a patient with IgE myeloma. J Immunol 1976; 117: 1139-1144.

5. Tada T, Okumura K, Platteau B, Beckers A, Bazin H. Half-lives of two types of rat homocytotropic antibodies in circulation and in the skin. Int Arch Allergy Appl Immunol 1975; 48: 116-131.

6. Tada T, Okumura K. Regulation of homocytotropic antibody formation in the rat. I. Feed-back regulation by passively administered antibody. $J$ Immunol 1971; 106: 1002-1011.

7. Nakasone T, Hanashiro K, Sugama I, Kosugi T, Sunagawa H. Availabilty of a modified method for cannulation into rat jugular vein for blood sampling. Med Biol 1998; 137: 31 [in Japanese].

8. Hanashiro K, Nakamura M, Tamaki N, Kosugi T. Production of monoclonal dinitrophenyl-specific rat IgE and establishment of an IgE-capture ELISA for estimating the concentration of rat IgE antibodies to dinitrophenyl-Ascaris suum. Int Arch Allergy Immunol 1996; 110 371-379.

9. Rowland M, TozerTN. Clinical Pharmacokinetics Concepts and Applications. London: Lea and Febiger, 1989.

10. Isersky C, Rivera J, Mims S, Triche TJ. The fate of IgE bound to rat basophilic leukemia cells. J Immunol 1979; 122: 1926-1936.

11. Watanabe $\mathbf{N}$, Owhashi M, Nawa Y. Clearance of passively transferred IgE antibody from peripheral blood of mast cell-deficient $\mathrm{W} / \mathrm{Wv}$ mice. Int Arch Allergy Appl Immunol 1986; 81: 385-387.

12. Chen SS. Mechanisms of IgE homeostasis: sequestration of IgE by murine type II IgE Fc receptor-bearing B cell hybridomas. J Immunol 1991; 147: $1581-1586$

13. Haba S, Ovary Z, Nisonoff A. Clearance of IgE from serum of normal and hybridoma-bearing mice. J Immunol 1985; 134: 3291-3297.

14. Nielsen K, Sheppard J, Holmes W, Tizard I. Experimental bovine trypanosomiasis: changes in the catabolism of serum immunoglobulins and complement components in infected cattle. Immunology 1978; 35: 811-816.

Received 24 April 2001;

Accepted 15 May 2001 


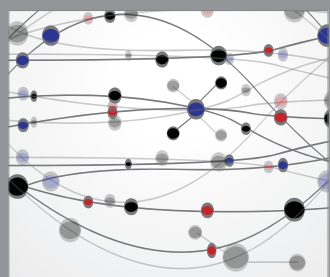

The Scientific World Journal
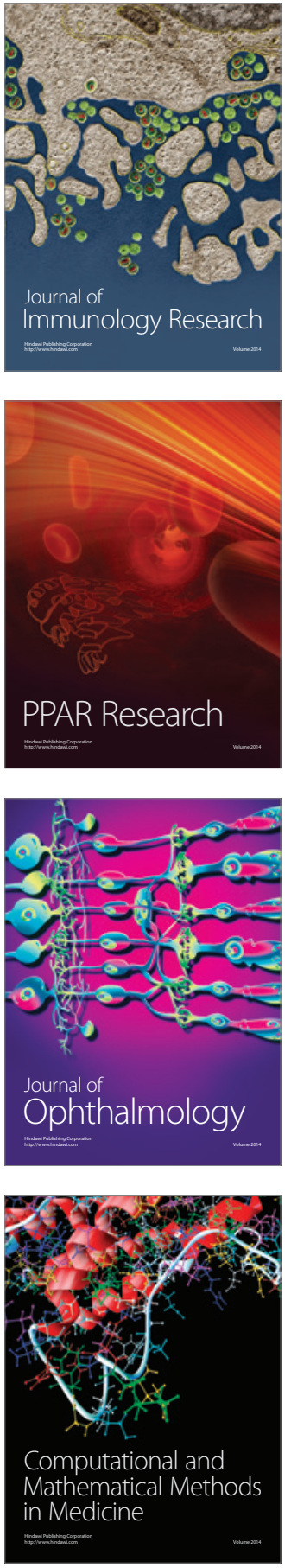

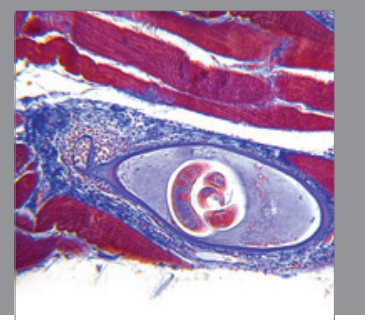

Gastroenterology

Research and Practice
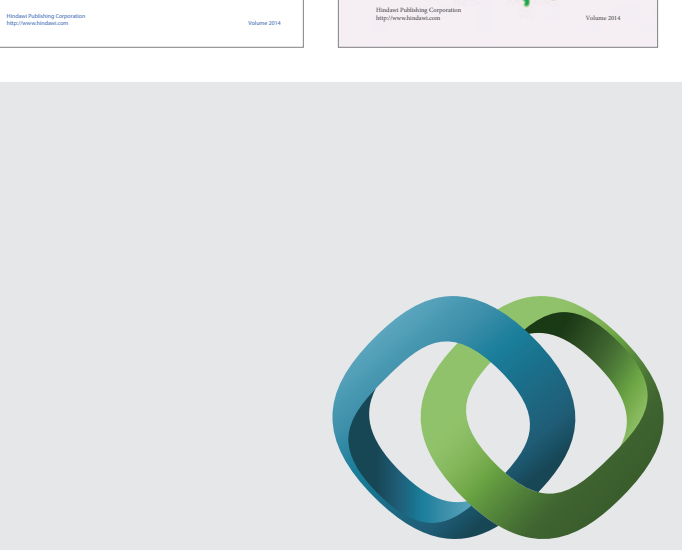

\section{Hindawi}

Submit your manuscripts at

http://www.hindawi.com
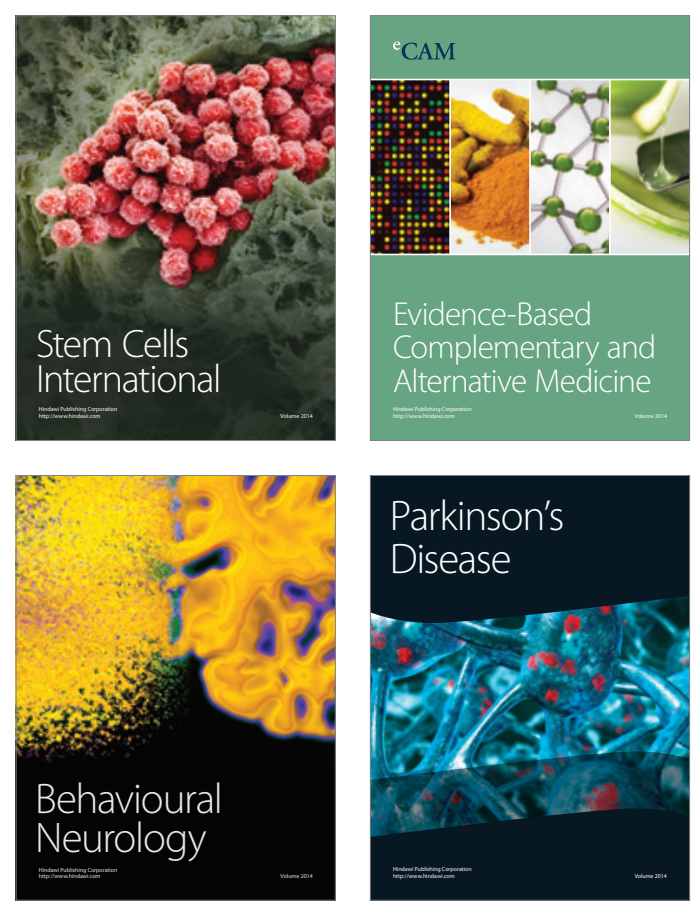

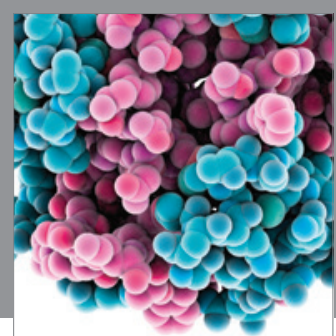

Journal of
Diabetes Research

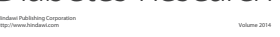

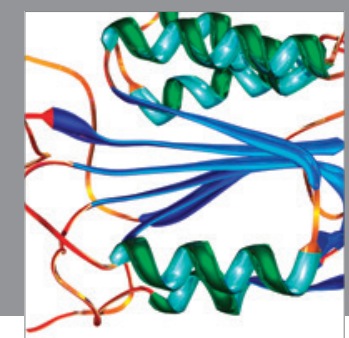

Disease Markers
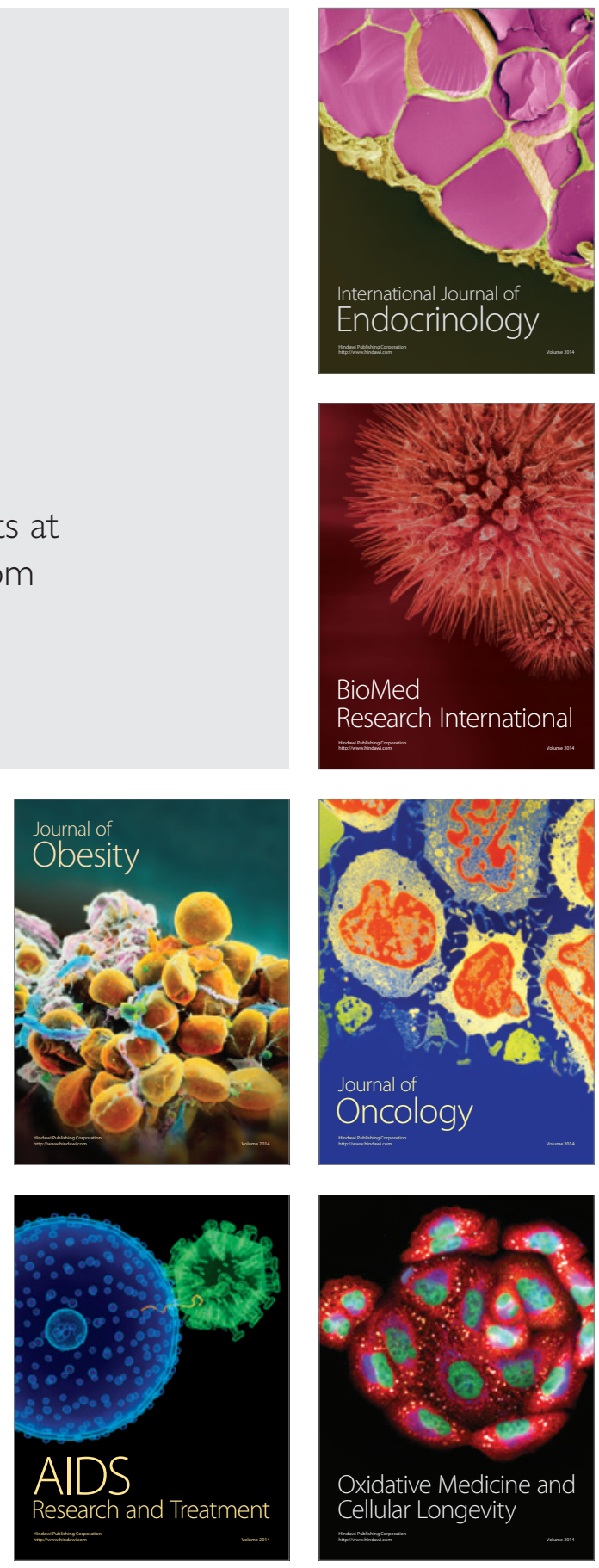